Tropical Journal of Pharmaceutical Research April 2020; 19 (4): 845-849

ISSN: $1596-5996$ (print); 1596-9827 (electronic)

(C) Pharmacotherapy Group, Faculty of Pharmacy, University of Benin, Benin City, 300001 Nigeria.

Available online at http://www.tjpr.org

Original Research Article

http://dx.doi.org/10.4314/tjpr.v19i4.24

\title{
Bronchodilatory effect of Zingiber officinale Roscoe (ginger) in guinea pigs
}

\author{
Jitendra H Vaghela1, Vishalkumar K Vadgama², Bhargav M Purohit ${ }^{2 *}$ \\ ${ }^{1}$ Department of Pharmacology, NAMO Medical Education \& Research Institute, Silvassa (Dadra and Nagar Haveli)-396230, \\ ${ }^{2}$ Department of Pharmacology, Government Medical College, Bhavnagar (Gujarat)-364001, India \\ *For correspondence: Email: drbhargavpurohit@gmail.com; Tel: +91-9725024978
}

Sent for review: 11 November 2019

Revised accepted: 22 January 2020

\begin{abstract}
Purpose: To determine the bronchodilatory effect of ginger on histamine-induced bronchospasm in guinea pigs.

Methods: Thirty-six guinea pigs weighing 400 - $700 \mathrm{~g}$ were randomly divided into six groups. Group 1 received distilled water, while group 2 was given formoterol $(1.55 \mu \mathrm{g} / \mathrm{kg})+$ budesonide $(0.02 \mathrm{mg} / \mathrm{kg})$. Guinea pigs in groups 3 and 4 were given ginger (350 and $700 \mathrm{mg} / \mathrm{kg}$, respectively), while those in groups 5 and 6 received ginger (350 and $700 \mathrm{mg} / \mathrm{kg}$, respectively) in addition to formoterol (1.55 $\mu \mathrm{g} / \mathrm{kg}$ ) and budesonide $(0.02 \mathrm{mg} / \mathrm{kg}$ ). Pre-convulsion time and percent protection in each group was calculated. Results: There was statistically significant improvement in pre-convulsion times, with values of 156.64 $\pm 32.93,299.33 \pm 44.20$, and $235.99 \pm 34.55 s$ for groups 2,5 and 6 , respectively $(p<0.01)$. Moreover, statistically significant protection values of 73 and $68 \%$ were obtained for groups 5 and 6 , respectively, relative to normal control $(p<0.01)$.

Conclusion: These results indicate that ginger has promising potential for use as an add-on treatment for bronchospasm.
\end{abstract}

Keywords: Zingiber officinale, Histamine, Asthma, Pre-convulsion time

\begin{abstract}
This is an Open Access article that uses a fund-ing model which does not charge readers or their institutions for access and distributed under the terms of the Creative Commons Attribution License (http://creativecommons.org/licenses/by/4.0) and the Budapest Open Access Initiative (http://www.budapestopenaccessinitiative.org/read), which permit unrestricted use, distribution, and reproduction in any medium, provided the original work is properly credited.

Tropical Journal of Pharmaceutical Research is indexed by Science Citation Index (SciSearch), Scopus, International Pharmaceutical Abstract, Chemical Abstracts, Embase, Index Copernicus, EBSCO, African Index Medicus, JournalSeek, Journal Citation Reports/Science Edition, Directory of Open Access Journals (DOAJ), African Journal Online, Bioline International, Open-J-Gate and Pharmacy Abstracts
\end{abstract}

\section{INTRODUCTION}

Asthma is characterized by chronic airway inflammation, with symptoms such as wheezing, shortness of breath, chest tightness and cough, as well as variable expiratory airflow limitation [1]. Asthma causes limitations in daily activities, loss of school and work days, lung function impairment, and reduced quality of life. Moreover, it is a source of huge socioeconomic burden. Studies have shown that about 15 million disability-adjusted life years are lost annually due to asthma, which represents $1 \%$ of the total global disease burden [2]. Although bronchodilators and inhalation corticosteroids are currently used for asthma management, the mortality, morbidity and asthma-related costs are challenging [3].

Complementary and alternative medicine (CAM) is widely used for managing asthma symptoms, but the exact mechanism of action of these agents is unclear [4]. Herbal drugs constitute a major portion of officially-recognized alternate 
systems of medicine practised in India, and more than $70 \%$ of the Indian population of 1.1 billion still use these non-allopathic systems of medicine due to their evidence-based safety [4].

Zingiber officinale Roscoe (ginger) is one of the common plants consumed worldwide as a spice and flavoring agent. In India, the average daily consumption of fresh ginger root is 8-10 $\mathrm{g}$ [5]. Ginger exerts pharmacological effects such as cardioprotective, anti-inflammatory, antimicrobial, anti-proliferative, neuroprotective, hepatoprotective and antioxidant properties [5]. Ginger is also a useful remedy for respiratory ailments like cough, cold and other respiratory problems [6]. Moreover, ginger has also been shown to possess bioactivity against respiratory ailments in various studies either by acting directly as a smooth muscle relaxant, or as an anti-inflammatory effect [7-10].

The present study was designed to evaluate the bronchodilatory effect of aqueous extract of rhizomes of Zingiber officinale Roscoe in a guinea pig model of bronchial hyperreactivity.

\section{EXPERIMENTAL}

\section{Reagents}

Histamine was procured from Sigma Aldrich, USA (H7125- Lot = BCBD6387V). Formoterol powder was purchased from Sigma Aldrich, USA (Batch no. 2.2/ld. 00JST5), while budesonide was product of Cipla Limited, Gujarat, India (Lot/Batch no. SA60305). Gingerol-based aqueous extract of Zingiber officinale Roscoe (5\%) was made by Kuber Impex Ltd, Indore, Madhya Pradesh, India (Batch no. KIL/DSHEB14/GNR/1403/100/B). Ethical approval was obtained from Institutional Animal Ethics Committee (IAEC), GMC, Bhavnagar [577/GO/Re/N/02/CPCSEA] for the protocol of the study (IAEC no. 45/2016). The study was conducted in the Department of Pharmacology, Government Medical College, Bhavnagar, Gujarat, India from August 2016 to April 2017.

The guinea pigs were handled with care as per internationally accepted guidelines and norms for handling and care of animals, as provided by CPCSEA, India [11,12]. Thirty-six healthy guinea pigs weighing between 400 and $700 \mathrm{~g}$ were used for the experiments. They were housed in standard transparent polypropylene cages with wheat husk bedding, and kept under controlled room temperature and humidity $\left(26 \pm 3{ }^{\circ} \mathrm{C} ; 40 \pm\right.$ $5 \%$ ) in a 12-h light/12-h dark cycle, and were given standard laboratory diet and water ad libitum.
After an overnight fast, the animals were exposed to inhalation of $0.5 \%$ histamine in a histamine chamber through a nebulizer [13]. The pre-convulsion time (PCT), i.e. the time from inhalation exposure to the start of dyspnoea leading to the appearance of convulsion, was recorded in seconds (T1). As soon as the asphyctic convulsion occurred, the animals were removed from the chamber and resuscitated with humidified oxygen given through a face mask. After 14 days of treatment with extract/standard drug, the animals were again exposed to $0.5 \%$ histamine inhalation, and pre-convulsion time was recorded (T2).

Histamine $(0.5 \% \mathrm{w} / \mathrm{v})$ inhalation was given in all groups on day 0 and day 14. Different groups received different treatment for 14 days. Group 1 (vehicle control) received $1 \mathrm{ml}$ distilled water orally. Group 2 (active control) received formoterol $(1.55 \mu \mathrm{g} / \mathrm{kg})$ and budesonide (0.02 $\mathrm{mg} / \mathrm{kg}$ ) by inhalation $[14,15]$. Group 3 (low-dose ginger) received Zingiber officinale Roscoe (350 $\mathrm{mg} / \mathrm{kg}$ ) orally, while group 4 (high-dose ginger) received Zingiber officinale Roscoe at a dose of $700 \mathrm{mg} / \mathrm{kg}$, also orally. Group 5 (active control + low-dose ginger) was given formoterol (1.55 $\mu \mathrm{g} / \mathrm{kg}$ ) and budesonide $(0.02 \mathrm{mg} / \mathrm{kg}$ ) through inhalation, in addition to Zingiber officinale Roscoe (350 mg/kg) orally. Group 6 (active control + high-dose ginger) received formoterol (1.55 $\mathrm{\mu g} / \mathrm{kg}$ ) and budesonide (0.02 $\mathrm{mg} / \mathrm{kg})$ through inhalation, and Zingiber officinale Roscoe $(700 \mathrm{mg} / \mathrm{kg})$ orally. Pre-convulsion time difference between day 0 and day 14 was obtained, and protection $(P)$ in each group was calculated using Eq 1.

$\mathrm{P}(\%)=\{(\mathrm{T} 2 \mathrm{~T} 1) / \mathrm{T} 2\} 100$

\section{Statistical analysis}

The differences between PCTs on day 0 and day 14 were compared using paired t-test. The values of percentage protection in the normal control group and active control group were compared with corresponding values for the other groups using One-way ANOVA. All statistical analyses were performed using GraphPad Instat trial version 3.06 (GraphPad Software Inc, San Diago, USA). Values of $p<$ 0.01 were considered significant.

\section{RESULTS}

The mean pre-drug and post-drug PCT values in different groups are depicted in Table 1. Distilled water produced no effect on the PCT in guinea pigs in group 1. There were significant increases in post-drug PCT values in group $2(p<0.01)$,

Trop J Pharm Res, April 2020; 19(4):846 
Table 1: Pre-convulsion time (PCT) of different groups on day 0 and day 14

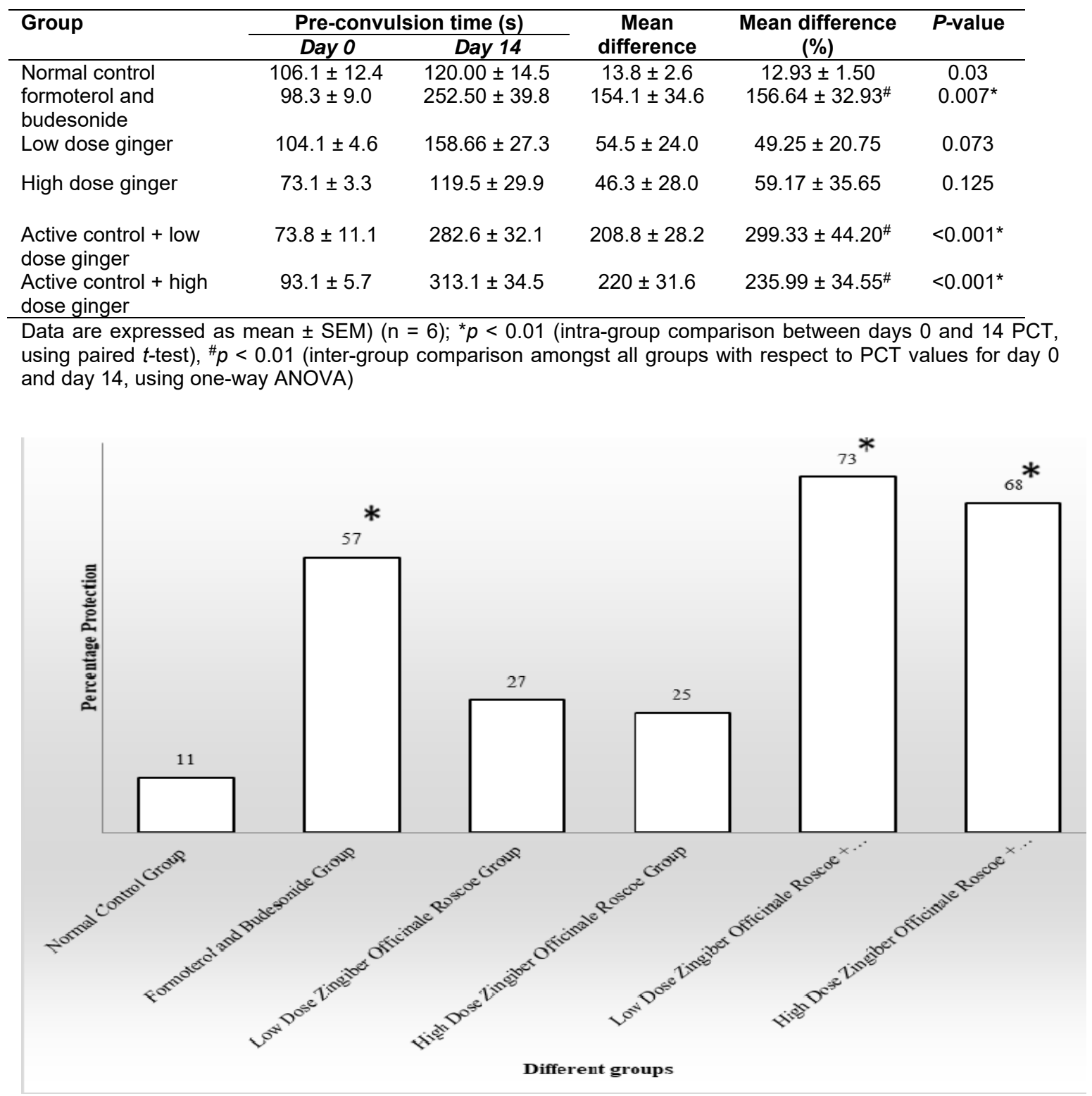

Figure 1: Protection provided by the various treatments $\left({ }^{*} p<0.01\right)$

group $5(p<0.01)$ and group $6(p<0.01)$, relative to pre-drug values. The mean values of $\%$ protection obtained for different groups are shown in Figure 1. There were significant increases in groups 5 and 6 , when compared to normal control group $(p<0.01)$. However, there were favorable increases in \% protection in the low-dose and high-dose Zingiber officinale Roscoe group, relative to normal control group, although these increases were not statistically significant $(p>0.01)$. Although the values of percentage protection in the low-dose Zingiber officinale Roscoe + formoterol + budesonide group (73.27 $\pm 3.08 \%$ ), and high-dose Zingiber officinale Roscoe + formoterol + budesonide group $(67.82 \pm 4.80 \%)$ were higher than that of the active control, i.e., formoterol + budesonide group alone $(56.67 \pm 6.83 \%)$, the difference between them was not statistically significant $(p$ $>0.01)$.

\section{DISCUSSION}

Herbal drugs are used for the treatment of various common ailments as a part of the traditional system of medicine, due to their potential efficacy. However, there is need to scientifically validate their pharmacological effects and their clinical efficacies. Newer drug 
targets need to be discovered rather than synthesizing more and more me-too drugs [16]. In the present study, an aqueous extract of Zingiber officinale Roscoe (ginger) was investigated with respect to its bronchodilatory effect in terms of pre-convulsion time and percentage protection in guinea pigs. In the normal control group as well as low- and highdose Zingiber officinale Roscoe groups, there were favorable, yet non-significant increases in pre-convulsion times between day 0 and day 14 . However, in the low-dose ginger groups, there were substantial increases in pre-convulsion time between day 0 and day 14, when compared with the normal control group. In formoterol and budesonide control groups, low-dose Zingiber officinale Roscoe + formoterol and budesonide control group, as well as high-dose Zingiber officinale Roscoe group, there were statistically significant increases in pre-convulsion time between day 0 and day 14 . An increase in preconvulsion time roughly corresponds to summation of the effect of the active control group and that of the respective ginger group alone group. This indicates that the effect of zingiber officinale Roscoe was additive. There were significant increases in percentage protection in formoterol + budesonide group, lowdose Zingiber officinale Roscoe + formoterol and budesonide group, and in high-dose Zingiber officinale Roscoe + formoterol and budesonide group, when compared to the normal control group.

In low- and high-dose Zingiber officinale Roscoe groups, there were also favorable, yet nonsignificant increases in percentage protection, relative to the active control group. The findings in the present study suggest potential protective effect of $5 \%$ gingerol-based aqueous extract of Zingiber officinale Roscoe against histamineinduced bronchospasm in guinea pigs. These findings also suggest that addition of formoterol and budesonide to Zingiber officinale Roscoe is therapeutically advantageous.

A study by Townsend et al has established independent as well as add-on effects of constituents of Zingiber officinale Roscoe i.e. 6gingerol, 8-gingerol, and 6-shagaol on isolated guinea pig and human tracheas challenged with bradykinin. They reported that 6 -shagaol caused significant relaxation of isolated guinea pig and human tracheas, when compared with 8-gingerol and 6-gingerol [9]. In addition, they established that there were significant potentiation of isoproterenol-induced relaxation with any of the constituents of Zingiber officinale Roscoe, while 6 -Shagaol was the most effective compound with the largest shift in $\mathrm{EC}_{50}$ [10]. It was also reported that 6-gingerol, 8-gingerol or 6-shagaol significantly inhibited PDE $4 \mathrm{D}$, and that in addition, 8-gingerol and 6-shagaol inhibited phospholipase $\mathrm{C}$ activity [10].

In addition, Ghayur et al. reported that modulation in inward calcium current might be a probable mechanism involved in ginger-induced airway smooth muscle relaxation [8]. This mechanism might be responsible for the effects of Zingiber officinale Roscoe observed in this study.

The results of the present study suggest that Zingiber officinale Roscoe provides better bronchodilator effect in the presence of formoterol and budesonide than when it is used alone. This may be due to the fact that $5 \%$ gingerol-based aqueous extract of Zingiber officinale Roscoe was used in the present study, while previous studies which reported significant positive effects used either the bioactive constituents alone (i.e. 6-shagaol) or crude extract which may have contained bioactive components other than gingerol. Previous studies reported positive effects of only one bioactive constituent of Zingiber officinale Roscoe i.e. isoproterenol. In present study, formoterol and budesonide were used.

\section{CONCLUSION}

The results obtained in this study show that the aqueous extract of Zingiber officinale Roscoe exhibits strong bronchodilator effect against histamine-induced bronchospasm in guinea pigs. The bronchodilator activity may be directly due to smooth muscle relaxation, inhibition of PDE $4 \mathrm{D}$ enzyme or anti-inflammatory effect. Thus, $5 \%$ gingerol-based aqueous extract of Zingiber officinale Roscoe has potential for clinical application in asthma treatment.

\section{DECLARATIONS}

\section{Acknowledgement}

I would like to acknowledge Dr CB Tripathi, Dean and Professor, Government Medical College, Bhavnagar for his thorough and kind support throughout the study, and also Dr. Jigna Dave, Professor and Head, Pulmonary Medicine Department. Special thanks also to Sir Takhtasinhji of General Hospital \& Government Medical College, Bhavnagar for his related clinical guidance regarding the project. 


\section{Conflict of interest}

No conflict of interest is associated with this work.

\section{Contribution of authors}

We declare that this work was done by the authors named in this article, and all liabilities pertaining to claims relating to the content of this article will be borne by the authors. Jitendra Vaghela designed the study, performed the experiments, and prepared and revised the manuscript. Vishal Vadgama conceptualized and designed this study, helped in analysis and interpretation of data, and participated in drafting and revising the manuscript. Bhargav Purohit conceptualized and designed study, helped in analysis and interpretation of data, and also took part in drafting and revising the manuscript.

\section{Open Access}

This is an Open Access article that uses a funding model which does not charge readers or their institutions for access and distributed under the terms of the Creative Commons Attribution License (http://creativecommons.org/licenses/by/ 4.0) and the Budapest Open Access Initiative (http://www.budapestopenaccessinitiative.org/rea d), which permit unrestricted use, distribution, and reproduction in any medium, provided the original work is properly credited.

\section{REFERENCES}

1. Global Initiative for Asthma. Global Strategy for Asthma Management and Prevention, 2017. Available from: http://www.ginasthma.org/

2. Koul PA, Patel D. Indian guidelines for asthma: Adherence is the key. Lung India: official organ of Indian Chest Society. 2015; 32(Suppl 1): S1.

3. Misra $\mathrm{KH}$, Kodanda Ramu B, Bandyopadhyay $M$. Evaluation of antiasthmatic effect of ethanol extract of Piper betle Linn. against histamine induced bronchospasm in guinea pigs. International Journal of Basic and applied chemical sciences. 2014; 4(1): 67-73.
4. Ashok DB, Thomas PA. Current status of herbal drugs in India: An overview. J Clin Biochem Nutr. 2007; 41(1): 11.

5. Singh SK, Patel JR, Bachle D. A review on zingiber officinale: a natural gift. International Journal of Pharma and Bio Sciences 2014; 5(3): 508-25.

6. Banerjee S, Mullick HI, Banerjee J, Ghosh A. Zingiber officinale: 'a natural gold'. Int J Pharmaceutical Bio-Sci. 2011; 2: 283-94.

7. Rouhi $H$, Ganji $F$, Nasri $H$. Effects of Ginger on the improvement of asthma [the evaluation of Its treatmental effects]. Pak J Nutr. 2006; 5(4): 373-6.

8. Ghayur MN, Gilani $A H$, Janssen LJ. Ginger attenuates acetylcholine-induced contraction and $\mathrm{Ca}+$ signalling in murine airway smooth muscle cells. Canadian journal of physiology and pharmacology 2008; 86(5): 264-71.

9. Townsend EA, Siviski ME, Zhang $Y, X u C$, Hoonjan B, Emala CW. Effects of ginger and its constituents on airway smooth muscle relaxation and calcium regulation. American journal of respiratory cell and molecular biology 2013; 48(2): 157-63.

10. Townsend EA, Zhang $Y, X u C$, Wakita R, Emala CW. Active components of ginger potentiate $\beta$-agonistinduced relaxation of airway smooth muscle by modulating cytoskeletal regulatory proteins. American journal of respiratory cell and molecular biology 2014; 50(1): 115-24.

11. CPCSEA guideline for animal handling and care in accordance with guidelines set by Committee for the Purpose of Control and Supervision of Experiments on Animals (CPCSEA), New Delhi, India. 2010; 22-56.

12. National Research Council (NRC). Guidance for the description of animal research in scientific publications. Washington, DC: National Academies Press, 2011.

13. Vogel HG, Vogel WH, editors. Drug discovery and evaluation: pharmacological assays. 2nd Ed. Springer Science \& Business Media 2013; 17: 362-64.

14. Rong X, Peng G, Suzuki T, Yang Q, Yamahara J, Li Y. A 35-day gavage safety assessment of ginger in rats. Regulatory Toxicology and Pharmacology 2009; 54(2) :118-23.

15. Medhi B, Prakash A. Practical manual of experimental and clinical pharmacology. 2nd Ed. Jaypee Brothers, Medical Publishers Pvt. Limited 2010: 23-24.

16. Beherra S K, Panigrahi A K, Mohapatra S., Bronchodilatory Effect of Inhaled Neem oil in Guinea pigs, International Journal of Innovative Research in Technology \& Science 2015; 2(3): 17-19. 